\title{
Charge Transfer Complexes of Gamma Aminobutyric Acid-Analogue, A Neurotransmitter: Synthesis and Spectrophotometric Determination Najma Sultana1 ${ }^{1}$ Muhammad Saeed Arayne ${ }^{2 *}$ and Saeeda Nadir $\mathrm{Ali}^{2 *}$
}

${ }^{1}$ Research Institute of Pharmaceutical Sciences, Faculty of Pharmacy, University of Karachi, Karachi-75270, Pakistan ${ }^{2}$ Department of Chemistry, University of Karachi, Karachi-75270, Pakistan

\begin{abstract}
Here, we report spectrophotometric method for the determination of gabapentin through charge transfer complexes with $\sigma$ and $\pi$ acceptors and also with dye stuffs. The method involves ion-pair complex formation of gabapentin with ninhydrin, 2,3-dichloro-5,6-dicyano-1,4-benzoquinone, tetracyanoethylene, methyl orange and picric acid. The optimum conditions for the reactions and validation of described procedure have been studied. Resulting complexes absorb at 580, 315, 340, 464 and 342 nm in the Beer's law range of 2-22, 32-80, 40-360, 12-96 and $15-135 \mu \mathrm{g} \mathrm{mL}^{-1}$ with correlation coefficient greater than 0.998 in each case respectively. The proposed method was applied successfully for the determination of gabapentin in pharmaceutical formulations. Satisfactory recovery values suggest that the method is reliable for the determination of gabapentin in pharmaceutical formulations without interference of excipients. In addition, the spectral characteristics including oscillator's strength, dipole moment, ionization potential, energy of complexes, resonance energy and also the thermodynamic parameters i.e. association constant and Gibb's free energy changes have been determined. Benesi-Hildebrand plots for each complex have been constructed. Further, solid charge transfer complexes of gabapentin were synthesized and characterized by IR spectroscopy.
\end{abstract}

Keywords: Charge transfer complexes; Gabapentin; $\sigma$ and $\pi$ acceptors; Dye stuffs; Benesi-Hildebrand plot

\section{Introduction}

Gabapentin (GBP) (Figure 1) is the analog of inhibitory neurotransmitter gamma aminobutyric acid (GABA) having a cyclohexyl ring at $\beta$-position. Even though, it structurally resembles with gamma aminobutyric acid but it is not mimetic of GABA. GBP is used to treat seizures caused by epilepsy, nerve pain caused by herpes virus or shingles; it may lower the number and intensity of hot flashes each day $[1,2]$. Administration of GBP does not affect cognitive functioning of patient [3]. It is a drug for post herpetic neuralgia and direct peripheral nerve injuries [4]. Even though, GBP is used as neuropathic pain relieving drug since last decade, but the mechanism by which it exerts its pharmacologic effects is not reported in literature yet. However, GBP is supposed to slow down the release of other neurotransmitters by participating in voltage-gated N-type calcium ion channels which actually causes less amount of calcium to reach the nerve terminals [5].

Charge transfer complex is a chemical association in which the attraction between the molecules is produced by an electronic transition to excited electronic state, resulting in transfer of electronic charge from donor having high ionization potential to acceptor having high electron affinity. These complexes are strongly colored and stable as solids as well as in solutions [6,7].

$\mathrm{UV}$-vis spectrophotometry is an easy and non-destructive technique for the detection and determination of a number of analytes

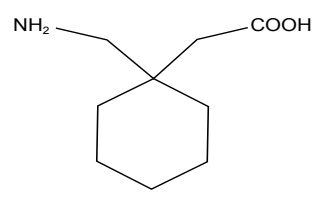

Figure 1: GBP in very simple manner. It usually involves economic reagents and not as much of analysis time is required for this method. In the past few years, different spectrophotometric methods have been developed by our research fellows [8-11]. Spectrophotometric methods for the determination of GBP in pharmaceutical formulations have also been reported by our research colleagues [12]. To date, the reported spectrophotometric methods for GBP determination include condensation with acetylacetone and formaldehyde by Hantzsch reaction [13], with vanillin in the presence of Mcllvain buffer $\mathrm{pH}$ 7.5 , ninhydrin (NIN) reagent in DMF medium and p-benzoquinone in ethanol medium [14], charge transfer complex formation with $\sigma$-acceptors: NIN [12] and iodine [15], with $\pi$-acceptors: 2,3 -dichloro5,6-dicyano-1,4-benzoquinone (DDQ), tetracyanoethylene (TCNE), tetracyanoquinodimethane (TCNQ), p-chloranilic acid and chloranil by Salem [15] and also by our research fellows [12] and with dyestuff bromocresol green and bromothymol blue [16] and also with picric acid (PA) and 2,4-dinitrophenol [17]. Other spectrophotometric methods include reaction of GBP with hypochloride in presence of Kolthoff buffer of pH 7.0 [18], simple UV-method [19] and automated spectrophotometry using piezoelectric pumping [20]. Besides, GBP is determined by liquid chromatography (HPLC) [21], gas chromatography-mass spectrometry (GC-MS) [22], capillary electrophoresis [23], spectrofluorimetry [24], potentiometry [25],

*Corresponding author: Saeed Arayne M, Research Institute of Pharmaceutical Sciences, Faculty of Pharmacy, University of Karachi, Karachi-75270, Pakistan, E-mail: saeeda_khowaja@hotmail.com

Received March 22, 2013; Accepted May 02, 2013; Published May 04, 2013

Citation: Najma S, Saeed Arayne M, Saeeda Nadir A (2013) Charge Transfer Complexes of Gamma Aminobutyric Acid-Analogue, A Neurotransmitter: Synthesis and Spectrophotometric Determination. J Bioanal Biomed 5: 013-021. doi:10.4172/1948-593X.1000075

Copyright: (C) 2013 Najma S, et al. This is an open-access article distributed under the terms of the Creative Commons Attribution License, which permits unrestricted use, distribution, and reproduction in any medium, provided the original author and source are credited. 
voltametry [26], chemiluminometry [27] and through electrochemical sensors [28].

This paper describes sensitive and rapid spectrophotometric method for the determination of GBP through derivatization with already reported reagents, like charge transfer complexes of GBP with NIN, DDQ, TCNE [12,15] and PA [17]. Present study differs in the manner that complexation has been carried out in low cost easily available solvent i.e. methanol. Secondly, none of these methods have reported spectral parameters; however the association constant and standard free energy changes have been reported in our previously reported method. Though, our earlier method involved the use of acetonitrile medium and the present study reports the formation of GBP charge transfer complexes in methanol or in aqueous medium for methyl orange (MO). The method is simple and reports many of spectral characteristics including oscillator's strength, dipole moment, ionization potential, energy of complexes, resonance energy and also the thermodynamic parameters i.e. association constant and Gibb's free energy changes which have never been determined yet. BenesiHildebrand plots for each complex have been constructed. Further, solid charge transfer complexes of GBP were synthesized and characterized by IR spectroscopy. Moreover, the developed methods have been successfully applied for the determination of GBP in pharmaceutical formulation without interference of excipients.

\section{Experimental}

\section{Materials and reagents}

Pure GBP was obtained from Godecke AG/Germany under license of Park-Davis. Pharmaceutical formulations Gabix capsules $100 \mathrm{mg}$ (Getz Pharmaceuticals (Pvt.) Ltd.) were purchased from the local pharmacy. NIN, DDQ, TCNE and MO were purchased from Merck Schuchardt OHG, Germany, where as and PA was obtained from Sigma Aldrich Chemie GmbH. All the solvents used were of analytical grade and double distilled de-ionized water was used throughout the analysis.

\section{Apparatus}

Electronic spectra of GBP and its complex were recorded in the region 200-800 $\mathrm{nm}$ using Shimadzu 1800 double beam UV-visible spectrophotometer version 3.9 software with quartz cells of $1.0 \mathrm{~cm}$ path length. The IR spectra were obtained from $\mathrm{KBr}$ discs using Shimadzu Prestige-21200VEC version 1.2 software.

\section{Standard stock solutions}

Stock solution of $0.1 \%$ pure GBP was prepared in analytical grade methanol. $1 \%$ solution of NIN, DDQ, TCNE and PA were prepared fresh daily in analytical grade methanol. MO was prepared in double distilled deionized water. Phthalate buffer of $\mathrm{pH}$ ranging from 2.2-4.0 was prepared by dissolving $20.4 \mathrm{~g}$ potassium hydrogen phthalate in 1.0 $\mathrm{L}$ distilled water and $\mathrm{pH}$ of solution was maintained by adding $0.1 \mathrm{M}$ HCl.

\section{Procedure for pure GBP}

Method for NIN: Serial volumes of drug solution in the concentration range of $2-22 \mu \mathrm{gmL}^{-1}$ was transferred into test tubes. To each test tube $2 \mathrm{~mL}$ of NIN reagent was added, and then heated on a water-bath at $50 \pm 1^{\circ} \mathrm{C}$ for $5 \mathrm{~min}$. The contents of the tubes were cooled at room temperature and then transferred into $10 \mathrm{~mL}$ volumetric flasks.
The volume was brought to mark with methanol and the absorbance was measured against reagent blank treated similarly.

Method for DDQ, TCNE and PA: For DDQ, TCNE and PA, $1 \mathrm{~mL}$ of them were placed into two different series of $10 \mathrm{ml}$ volumetric flasks. Then an appropriate volume of GBP solution (32-80, 40-360 and 15$135 \mu \mathrm{gmL}^{-1}$ for DDQ, TCNE and PA) was added to each flask. All the solutions were allowed to react at room temperature for $15 \mathrm{~min}$. The volume was made up to the mark with methanol and the absorbance was measured against reagent blank treated similarly.

Method for MO: Into a series of $10 \mathrm{~mL}$ volumetric flaks, aliquots of GBP solutions were transferred to get final concentration range 12-96 $\mu \mathrm{gmL}^{-1}$. To each flask, $3.0 \mathrm{~mL}$ buffer of $\mathrm{pH} 3.0$ and $3 \mathrm{~mL}$ MO solution was added and the volume was completed with distilled water. The contents were transferred to a $50 \mathrm{~mL}$ separating funnel and extracted with $20 \mathrm{~mL}$ chloroform in two portions. The absorbance of extracted organic layer was measured against reagent blank treated similarly. The standard calibration graphs of all charge transfer complexes were prepared by plotting absorbance vs. concentration of GBP.

\section{Procedures for pharmaceuticals formulation}

Twenty Gabix ${ }^{\circledR}$ capsules $(100 \mathrm{mg}$ ) were finely powdered. The powder equivalent to $100 \mathrm{mg}$ of GBP was dissolved in methanol and shaken well for proper mixing. This solution was allowed to stand for $30 \mathrm{~min}$ and then sonicated for complete solubilization of drugs. Then the contents were filtered to separate the insoluble excipients and volume was completed with same solvent to get $0.1 \%$ GBP solution. The procedure was continued as described under the procedure for pure GBP.

\section{Synthesis of solid charge transfer Complexes}

Synthesis of GBP charge transfer complexes was carried out by refluxing the GBP with each of the complexing agent separately for $2 \mathrm{hrs}$ in the ratio of 1:1 and 1:2 for NIN as found through the stoichiometric study by applying Job's method. The resulting product in each case was filtered off and washed with minimum amount of methanol. The excess solvent was evaporated to dryness. The solid charge transfer complexes were characterized by UV-visible and IR spectroscopy.

\section{Results and Discussion}

\section{Absorption spectra}

We reported charge transfer complexes of GBP with NIN and $\pi$ acceptors in acetonitrile medium [12]. In the present study, formation of GBP charge transfer complexes with NIN, DDQ, TCNE and PA in methanol or in aqueous medium for MO has been described. The complexes showed Ruhemann purple, red, bluish green, red and dark yellow coloration with $\lambda_{\max } 315,340,580,464$ and $342 \mathrm{~nm}$ respectively. The absorption spectra of these complexes are shown in figure 2 .

\section{Stoichiometry of the reaction}

The reaction stoichiometries between GBP and complexing agents were determined by measuring the absorbance of complex solutions containing the drug solution and complexing agents in ratios $(0: 10$, $1: 9 \ldots . .10: 0)$. The results indicated that the charge transfer interaction of GBP occurs on an equimolar basis (1:1) with all the complexing agents and 1:2 for ninhydrin (Figure 3).

\section{Optimization of reaction time}

The optimum heating time for GBP-NIN complex formation was 


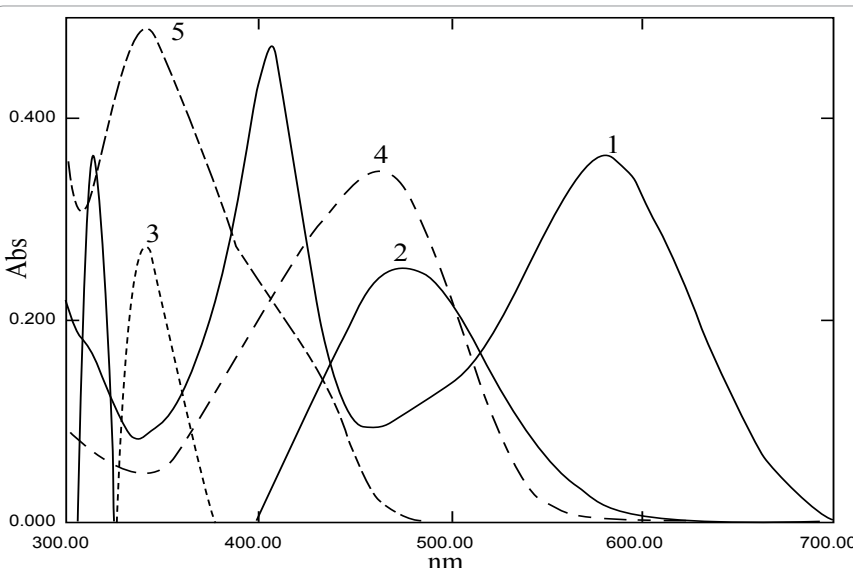

Figure 2: UV spectra of charge transfer complexes of GBP with (1) NIN (2) DDQ (3) TCNE (4) MO (5) PA. determined by following the absorbance at different time intervals. The contents were refluxed on water bath at $55 \pm 1^{\circ} \mathrm{C}$. After every minute, one of the tubes was removed; the procedure was applied to obtain ten readings. It is evident from (Figure 4) that complete complexation occurred at $5 \mathrm{~min}$. and the absorbance remained constant up to 10 min. Therefore, the complete reaction time was considered to be 5 min. The optimum reaction time for GBP with $\pi$-acceptors and PA were determined by monitoring the color development at different time interval at room temperature $\left(25 \pm 1^{\circ} \mathrm{C}\right)$. The complete color development was attained instantaneously and was stable for more than $24 \mathrm{hr}$ (Figure 5). The maximum absorption for GBP-MO complex was attained after proper shaking of mixture up to $2 \mathrm{~min}$ and it also found to be stable for $24 \mathrm{hr}$. The effect of reagent concentration is apparent from figure 6 that increased volume of complexing agent does not persuade the absorbance of complex and $2.0 \mathrm{~mL}$ of $1 \% \mathrm{NIN}, 1.0$ $\mathrm{mL}$ of $1 \% \mathrm{DDQ}$, TCNE and PA solutions and $3 \mathrm{~mL}$ of $1 \% \mathrm{MO}$ solution

(a) 0.40

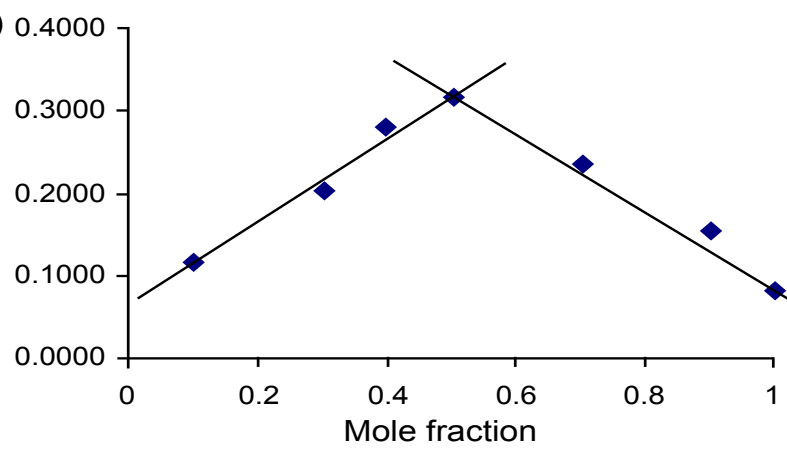

(c)

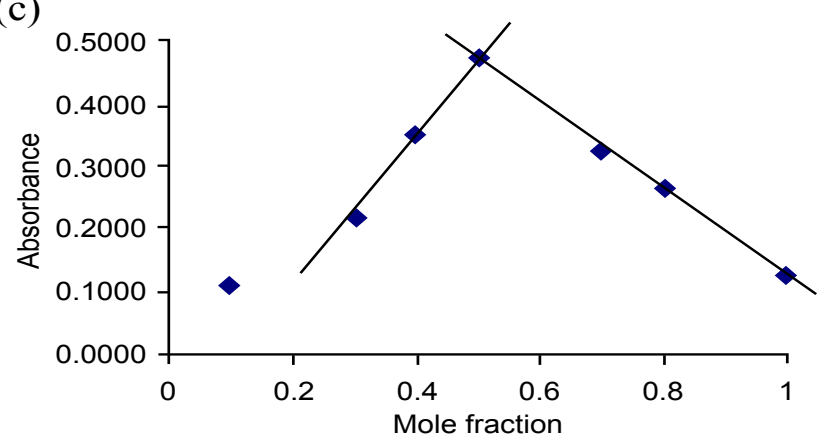

(e)

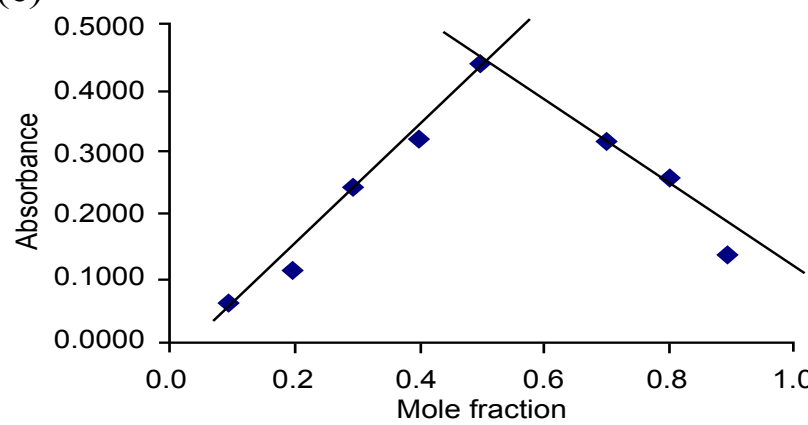

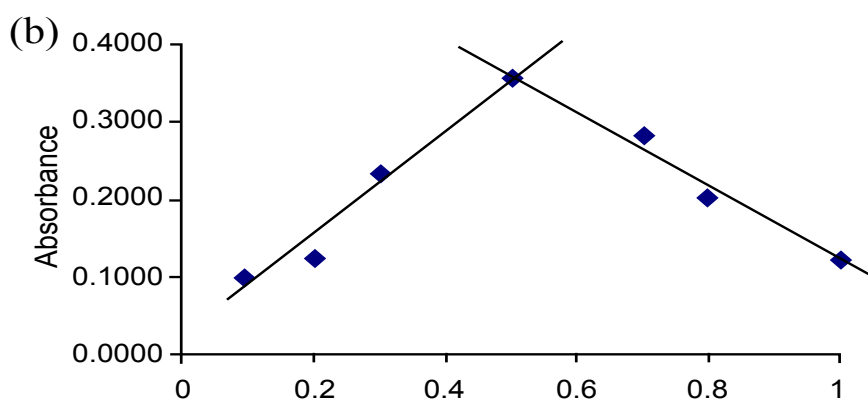

Mole fraction

(d)

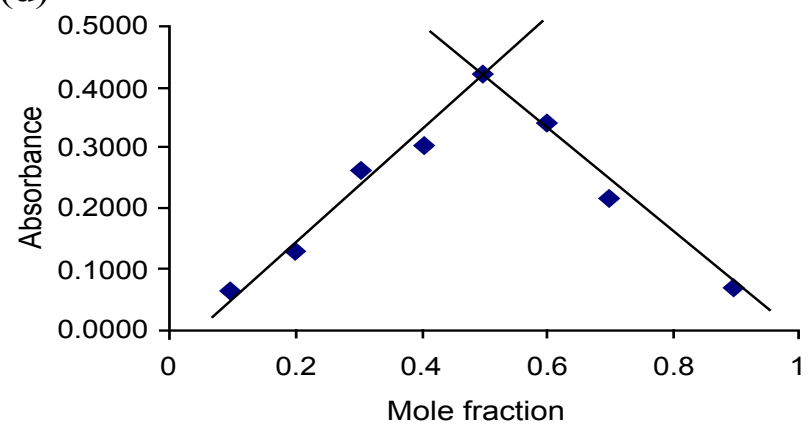

Figure 3: Job's plot for charge transfer complexes of GBP with (1) NIN (2) DDQ (3) TCNE (4) MO (5) PA. 
are sufficient for complete complexation. For MO method, buffer of suitable $\mathrm{pH}$ was selected by testing them in the range of 2.0-4.0 and the maximum absorbance was obtained at $\mathrm{pH} 3.0$ (Figure 7). For proper extraction of complex, solvents like benzene, carbon tetra chloride, dichloromethane and chloroform were tested. Double extraction with chloroform was supposed to be adequate for maximum recovery.

\section{Method validation}

Under the optimized experimental conditions, the calibration graphs plotted between absorbance verses concentration of GBP were found to be linear. Beer's law ranges were obtained to be 2-22, 32-80, 40-360, 12-96 and 15-135 $\mu \mathrm{g} \mathrm{mL}^{-1}$ for NIN, DDQ, TCNE, MO and PA with correlation coefficient greater than 0.998 for all the complexes. Regression characteristics including slope, intercept, correlation coefficient and also the molar absorptivity values are given in table 1 . Limit of detection and quantitation were determined to establish the sensitivity of method. The LOD values were calculated to be 320,150 , 680, 960 and $410 \mathrm{ng} \mathrm{mL}^{-1}$ respectively (Table 1 ).

The proposed method was applied on five replicates of GBP at seven concentration level to test the precision of method. The measurements of relative standard deviation obtained for each method are reported in table 2 . The low $\%$ RSD values confirm the sensitivity of method. For the determination of accuracy, the percent recovery of GBP through proposed method was calculated. Satisfactory values of recovery (Table 3) concluded that the method is free from constant error.

The high values of molar absorptivity of the resulting colored

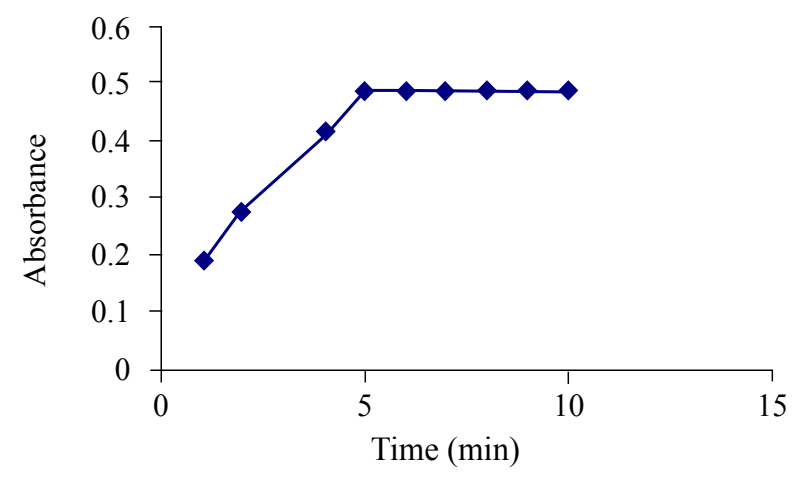

Figure 4: Effect of heating time on GBP-NIN complex.

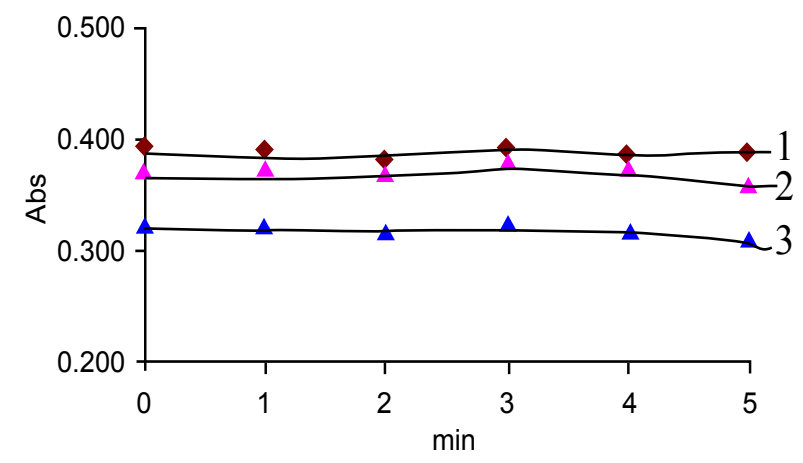

Figure 5: Reaction time for charge transfer complexes of GBP with (1) DDQ (2) TCNE (3) PA.
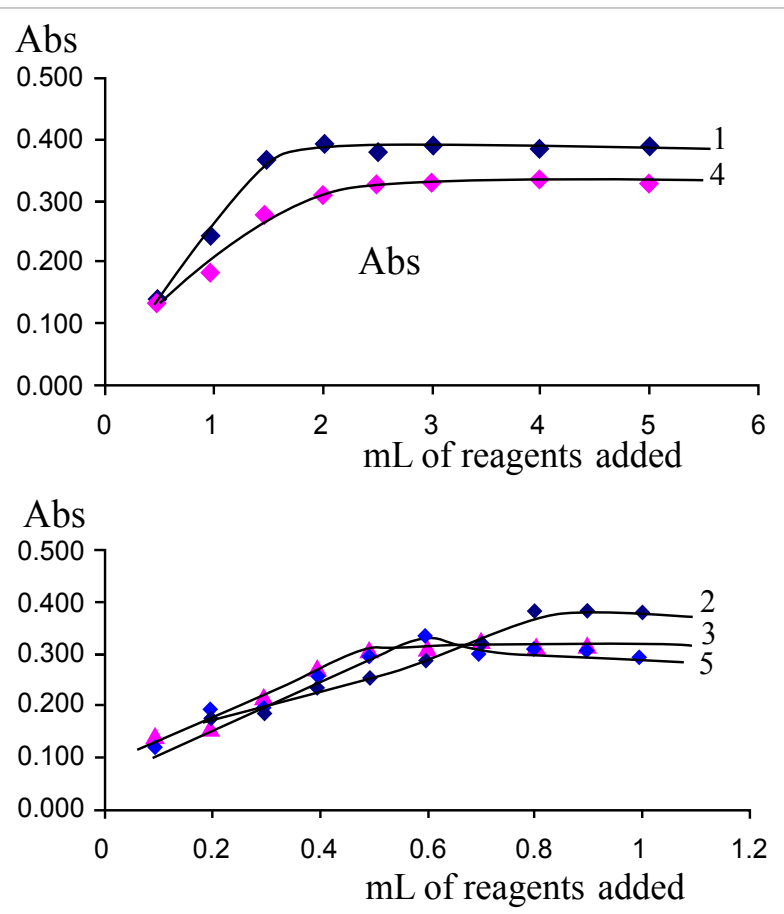

Figure 6: Effect of $\mathrm{mL}$ of reagent on charge transfer complexes of GBP with (1) NIN (2) DDQ (3) TCNE (4) MO (5) PA.

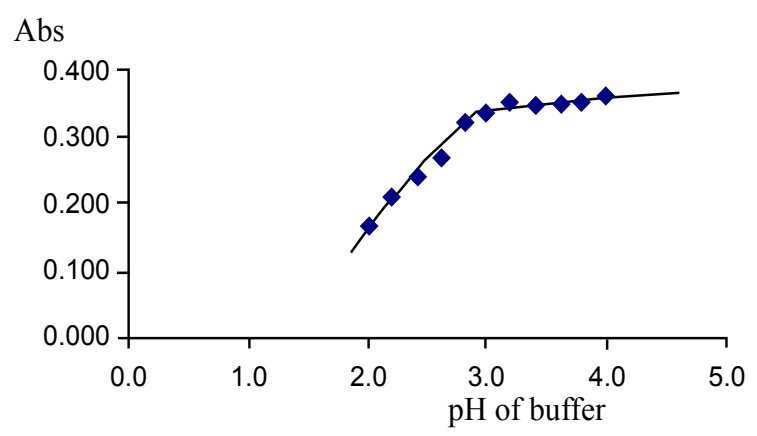

Figure 7: Effect of $\mathrm{pH}$ on GBP-MO complex.

complexes indicate the high sensitivity of the methods. High value of correlation coefficient confirms the best linearity of the calibration curve. The value of detection limit and variance speak of good sensitivity of the proposed method and negligible disperse of the calibration data around the line of regression. Therefore, it is concluded that the proposed method is free from constant error independent of the GBP concentration.

\section{Pharmaceutical formulation}

The developed charge transfer methods were successfully applied for the determination of GBP in its dosage formulation by five replicate determinations. The results obtained are shown in table 3. Satisfactory recovery data was obtained in the range of $99.23-100.80 \%$, 98.46100.64\%, 99.32.46-101.82\%, 98.02-100.31\% and $99.93-101.15 \%$ for NIN, DDQ, TCNE, MO and PA. The low percent error indicated the reliability of method. The assay results were in good agreement with the label claim. Commonly present excipients did not interfere during the assay. 
Citation: Najma S, Saeed Arayne M, Saeeda Nadir A (2013) Charge Transfer Complexes of Gamma Aminobutyric Acid-Analogue, A Neurotransmitter: Synthesis and Spectrophotometric Determination. J Bioanal Biomed 5: 013-021. doi:10.4172/1948-593X.1000075

\section{Effect of excipients}

A systemic study was performed to determine the effect of inactive ingredients commonly used in pharmaceutical formulation by scanning the blank solution containing $10 \mathrm{mg} \mathrm{GBP}$ and also the placebo solutions prepared by separately mixing $10 \mathrm{mg}$ of GBP with pyrrolidone ( $10 \mathrm{mg})$, lactose $(10 \mathrm{mg})$, talc $(20 \mathrm{mg})$, magnesium stearate $(15 \mathrm{mg})$ and starch (10 mg) in $100 \mathrm{~mL}$ volumetric flask. The percent recovery values given in table 4 indicate that there is no effect of common excipients present in pharmaceutical formulation.

\section{Spectral characteristics of charge transfer complexes}

The experimental oscillator strength (f) and transition dipole moment $(\mu)$ of newly formed charge transfer complexes were determined by formulae given in equation (1) and (2) [29,30];

$$
\begin{aligned}
& \mathrm{f}=\left(4.319 \times 10^{-9}\right) \varepsilon_{\max } \cdot v_{1 / 2} \\
& \mu=0.0958\left(\varepsilon_{\max } \cdot v_{1 / 2} / v_{\max }\right)^{1 / 2}
\end{aligned}
$$

where $\varepsilon_{\max }$ is the molar extinction coefficient at maximum absorbance, $v_{1 / 2}$ is the band-width at half absorbance in $\mathrm{cm}^{-1}$ and $v_{\max }$ is wave number in $\mathrm{cm}^{-1}$. Relatively large values of oscillator strength indicate the strength of complexes. The ionization potential (Ip) of free donor was calculated by using the equation (3) [31],

$$
\mathrm{I}_{\mathrm{p}}=5.76+1.53 \times 10^{-4} v_{\mathrm{CT}}
$$

where $v_{\mathrm{CT}}$ is the wave number in $\mathrm{cm}^{-1}$ corresponding to the charge transfer band of complex formed between donor and acceptor. The resonance energy of charge transfer complex in the ground state was determined by Brieglab and Czekalla equation (4) given below [32]:

$$
\varepsilon_{\max }=7.7 \times 10^{-4} /\left[\mathrm{h} v_{\mathrm{CT}} / \mathrm{R}_{\mathrm{N}}-3.5\right]
$$

\begin{tabular}{|c|c|c|c|c|c|}
\hline Parameters & GBP-NIN & GBP-DDQ & GBP-TCNE & GBP-MO & GBP-PA \\
\hline$\lambda_{\max }(n m)$ & $580 \mathrm{~nm}$ & $315 \mathrm{~nm}$ & $340 \mathrm{~nm}$ & 464 & 342 \\
\hline Linearity range $\mu \mathrm{gmL}^{-1}$ & $2-22$ & $32-80$ & $40-360$ & $12-96$ & $15-135$ \\
\hline Molar absorptivity & 632 & 2857 & 406 & 1542 & 2174 \\
\hline Slope & 0.0037 & 0,0287 & 0.0240 & 0.008 & 0.0063 \\
\hline Intercept & -0.0166 & -0.8723 & -0.0143 & 0.0472 & 0.1851 \\
\hline Correlation coefficient & 0.9985 & 0.9998 & 0.9999 & 0.9981 & 0.9983 \\
\hline LOD ngmL-1 & 320 & 150 & 680 & 960 & 410 \\
\hline $\mathrm{LOQ}_{\mu \mathrm{gmL}}{ }^{-1}$ & 0.96 & 0.44 & 2.06 & 2.92 & 1.23 \\
\hline
\end{tabular}

where $\mathrm{h}$ is the plank's constant and $v_{\mathrm{CT}}$ is the wave number in $\mathrm{cm}^{-1}$.

The energy of charge transfer complexes was calculated by applying

\begin{tabular}{|c|c|c|c|c|c|c|c|c|c|}
\hline \multicolumn{2}{|c|}{ GBP-NIN } & \multicolumn{2}{|c|}{ GBP-DDQ } & \multicolumn{2}{|c|}{ GBP-TCNE } & \multicolumn{2}{|c|}{ GBP-MO } & \multicolumn{2}{|c|}{ GBP-PA } \\
\hline Conc & \%RSD & Conc & \%RSD & Conc & \%RSD & Conc & \%RSD & Conc & \%RSD \\
\hline 20 & 0.81 & 36 & 0.83 & 40 & 1.28 & 12 & 1.41 & 15 & 0.28 \\
\hline 60 & 1.25 & 40 & 0.47 & 80 & 0.48 & 24 & 0.18 & 30 & 1.83 \\
\hline 80 & 0.56 & 48 & 1.67 & 120 & 0.48 & 36 & 0.20 & 60 & 0.34 \\
\hline 100 & 0.48 & 52 & 0.37 & 160 & 0.34 & 48 & 0.03 & 75 & 0.81 \\
\hline 120 & 0.10 & 56 & 0.29 & 200 & 1.28 & 60 & 0.22 & 90 & 0.48 \\
\hline 140 & 0.94 & 60 & 0.40 & 240 & 0.72 & 72 & 0.17 & 105 & 0.26 \\
\hline 160 & 0.30 & 68 & 1.10 & 280 & 0.68 & 84 & 0.13 & 135 & 0.05 \\
\hline
\end{tabular}
the relationship given in equation (5) [30]:

\begin{tabular}{|c|c|c|c|c|c|c|c|c|c|}
\hline \multicolumn{2}{|c|}{ GBP-NIN } & \multicolumn{2}{|c|}{ GBP-TCNE } & \multicolumn{2}{|c|}{ GBP-DDQ } & \multicolumn{2}{|c|}{ GBP-MO } & \multicolumn{2}{|c|}{ GBP-PA } \\
\hline$\% \operatorname{Rec}$ & $\%$ Err & $\% \operatorname{Rec}$ & $\%$ Err & $\% \operatorname{Rec}$ & $\%$ Err & $\% \operatorname{Rec}$ & $\%$ Err & $\% \operatorname{Rec}$ & $\%$ Err \\
\hline 100.61 & -0.61 & 99.34 & 0.66 & 101.82 & -1.82 & 98.02 & 1.98 & 100.39 & -0.39 \\
\hline 100.80 & -0.80 & 100.53 & -0.53 & 100.68 & -0.68 & 100.25 & -0.25 & 100.49 & -0.49 \\
\hline 100.69 & -0.69 & 99.59 & 0.41 & 99.32 & 0.68 & 100.28 & -0.28 & 101.15 & -1.15 \\
\hline 100.14 & -0.14 & 99.44 & 0.56 & 100.48 & -0.48 & 99.09 & 0.91 & 100.69 & -0.69 \\
\hline 100.43 & -0.43 & 100.64 & -0.64 & 101.02 & -1.02 & 100.31 & -0.31 & 100.37 & -0.37 \\
\hline 99.23 & 0.77 & 98.46 & 1.54 & 100.97 & -0.97 & 100.25 & -0.25 & 99.93 & 0.07 \\
\hline 99.15 & 0.85 & 100.76 & -0.76 & 101.48 & -1.48 & 100.18 & -0.18 & 100.06 & -0.06 \\
\hline
\end{tabular}

Table 1: Optimum conditions and analytical parameters.

Table 2: Precision of method.

Table 3: Accuracy of method. 
Citation: Najma S, Saeed Arayne M, Saeeda Nadir A (2013) Charge Transfer Complexes of Gamma Aminobutyric Acid-Analogue, A Neurotransmitter: Synthesis and Spectrophotometric Determination. J Bioanal Biomed 5: 013-021. doi:10.4172/1948-593X.1000075

$$
\mathrm{E}_{\mathrm{CT}}=1243.667 / \lambda_{\mathrm{CT}}
$$

where $\lambda_{\mathrm{CT}}$ is the wavelength of charge transfer band at maximum absorbance. All the spectral data including oscillator strength, dipole moment, ionization potential, resonance energy and energy of charge transfer complexes are presented in table 5.

The association constant was determined by employing BenesiHildebrand equation $[33,34]$.

$$
\Delta \mathrm{G}^{\circ}=-2.303 \mathrm{RT} \log \mathrm{K}_{\mathrm{C}}
$$

where, $\mathrm{K}$ is the association constant, $\mathrm{A}$ is absorbance, $\varepsilon$ is molar extinction coefficient and $\left[\mathrm{A}_{\mathrm{o}}\right]$ and $\left[\mathrm{D}_{\mathrm{o}}\right]$ are the initial concentrations of the acceptor and donor respectively. The values for $\mathrm{Kc}$ are given in table 5. Further investigation was made by plotting the values of $1 / \mathrm{D}_{0}$ versus $\mathrm{A}_{0} / \mathrm{A}$, which showed linear curve in all the cases. Table 6 presents the values and the graphs are displayed in figure 8 .

The standard free energy changes $\left(\Delta \mathrm{G}^{\circ}\right)$ associated with GBP complexation reactions were calculated from the association constants by applying equation (2). The values of $\Delta \mathrm{G}^{\circ}$ for each complex are given

\begin{tabular}{|c|c|c|c|c|c|}
\hline \multirow[t]{2}{*}{ Excipients } & $\begin{array}{l}\text { GBP- } \\
\text { NIN }\end{array}$ & $\begin{array}{l}\text { GBP- } \\
\text { DDQ }\end{array}$ & $\begin{array}{l}\text { GBP- } \\
\text { TCNE }\end{array}$ & $\begin{array}{l}\text { GBP- } \\
\text { MO }\end{array}$ & $\begin{array}{c}\text { GBP- } \\
\text { PA }\end{array}$ \\
\hline & \multicolumn{5}{|c|}{$\%$ Recovery } \\
\hline Pyrrolidone & 99.31 & 100.26 & 101.62 & 99.14 & 99.41 \\
\hline Lactose & 100.34 & 101.60 & 100.45 & 99.36 & 99.73 \\
\hline Talc & 99.00 & 99.08 & 99.12 & 101.14 & 99.01 \\
\hline Magnesium stearate & 99.43 & 99.48 & 99.40 & 100.37 & 100.23 \\
\hline Starch & 100.69 & 99.96 & 99.49 & 99.48 & 99.84 \\
\hline
\end{tabular}
in table 5.

\begin{tabular}{|c|c|c|c|c|c|c|c|}
\hline Complex & $f$ & $\mu$ & Ip & $\mathrm{E}_{\mathrm{CT}}$ & $\mathbf{R}_{\mathrm{N}}$ & $\begin{array}{l}\mathrm{Kc} \times 10^{2} \\
(\mathrm{lit} / \mathrm{mol})\end{array}$ & $\begin{array}{c}\Delta \mathbf{G}^{\circ} \\
(\mathrm{KCal})\end{array}$ \\
\hline GBP-NIN & 0.24 & 5.48 & 8.40 & 2.14 & 0.61 & 2.25 & 3.20 \\
\hline GBP-DDQ & 1.27 & 10.88 & 8.99 & 2.62 & 0.75 & 2.73 & 3.32 \\
\hline GBP-TCNE & 0.57 & 6.39 & 10.26 & 3.66 & 1.05 & 1.75 & 3.05 \\
\hline GBP-MO & 0.56 & 7.42 & 9.06 & 2.69 & 0.77 & 3.79 & 3.51 \\
\hline GBP-PA & 0.97 & 8.36 & 10.26 & 3.66 & 1.05 & 1.77 & 3.06 \\
\hline
\end{tabular}

Table 4: Recovery of GBP in presence of different excipients.

\begin{tabular}{|c|c|c|c|c|c|}
\hline Complex & $\begin{array}{l}\mathrm{D}(\mathrm{M}) \\
\times 10^{-3}\end{array}$ & $\begin{array}{l}\text { A (M) } \\
\times 10^{-3}\end{array}$ & Abs & $\begin{array}{c}1 / D \\
\times 10^{3}\end{array}$ & $\begin{array}{l}\text { A/Abs } \\
\times 10^{-2}\end{array}$ \\
\hline \multirow{5}{*}{$\begin{array}{l}\text { GBP- } \\
\text { NIN }\end{array}$} & 0.58 & 5.62 & 0.3497 & 1.71 & 1.61 \\
\hline & 0.70 & 5.62 & 0.4233 & 1.43 & 1.33 \\
\hline & 0.82 & 5.62 & 0.5164 & 1.22 & 1.09 \\
\hline & 0.99 & 5.62 & 0.6257 & 1.01 & 0.90 \\
\hline & 1.28 & 5.62 & 0.7983 & 0.78 & 0.70 \\
\hline \multirow{5}{*}{$\begin{array}{l}\text { GBP- } \\
\text { DDQ }\end{array}$} & 0.30 & 4.08 & 0.6246 & 3.29 & 0.65 \\
\hline & 0.33 & 4.08 & 0.7332 & 3.06 & 0.60 \\
\hline & 0.35 & 4.08 & 0.8510 & 2.85 & 0.48 \\
\hline & 0.37 & 4.08 & 0.9615 & 2.68 & 0.42 \\
\hline & 0.40 & 4.08 & 1.0862 & 2.52 & 0.38 \\
\hline \multirow{5}{*}{$\begin{array}{l}\text { GBP- } \\
\text { TCNE }\end{array}$} & 1.17 & 7.81 & 0.4677 & 0.86 & 1.67 \\
\hline & 1.40 & 7.81 & 0.5684 & 0.71 & 1.37 \\
\hline & 1.64 & 7.81 & 0.6578 & 0.61 & 1.19 \\
\hline & 1.87 & 7.81 & 0.7615 & 0.54 & 1.03 \\
\hline & 2.10 & 7.81 & 0.8546 & 0.48 & 0.91 \\
\hline \multirow{5}{*}{$\begin{array}{c}\text { GBP- } \\
\text { MO }\end{array}$} & 0.21 & 3.06 & 0.3241 & 4.76 & 0.94 \\
\hline & 0.28 & 3.06 & 0.4051 & 3.57 & 0.75 \\
\hline & 0.35 & 3.06 & 0.4808 & 2.85 & 0.64 \\
\hline & 0.42 & 3.06 & 0.6091 & 2.38 & 0.50 \\
\hline & 0.49 & 3.06 & 0.7332 & 2.04 & 0.42 \\
\hline \multirow{5}{*}{$\begin{array}{c}\text { GBP- } \\
\text { PA }\end{array}$} & 0.35 & 4.37 & 0.5556 & 2.85 & 0.79 \\
\hline & 0.44 & 4.37 & 0.6517 & 2.28 & 0.67 \\
\hline & 0.53 & 4.37 & 0.7434 & 1.90 & 0.59 \\
\hline & 0.61 & 4.37 & 0.8603 & 1.63 & 0.51 \\
\hline & 0.79 & 4.37 & 1.1610 & 1.27 & 0.38 \\
\hline
\end{tabular}

Table 5: Spectrophotometric results.

Table 6: The values of $\left[A_{0}\right] / A b s$ and $1 /\left[D_{0}\right]$ for GBP complexes. 


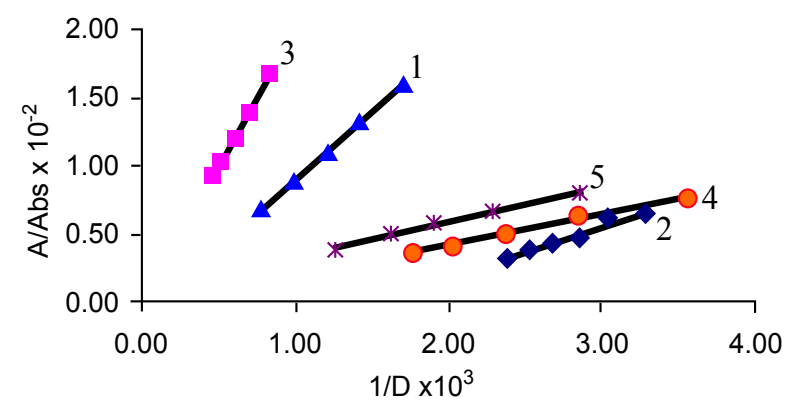

Figure 8: BH plot for charge transfer complexes of GBP with (1) NIN (2) DDQ (3) TCNE (4) MO (5) PA.

$$
\Delta \mathrm{G}^{\circ}=-2.303 \mathrm{RT} \log \mathrm{K}_{\mathrm{C}}
$$

where, $\Delta \mathrm{G}^{\circ}$ is the free energy change of the complex in $\mathrm{KJ} \mathrm{mol}^{-1}, \mathrm{R}$ is the gas constant $\left(1.987 \mathrm{cal} \mathrm{mol}^{-1} \mathrm{deg}^{-1}\right), \mathrm{T}$ is temperature in Kelvin and $\mathrm{K}_{\mathrm{c}}$ is the association constant of drug-acceptor complexes.

\section{Spectroscopic study}

Corresponding to the previously reported IR spectra of GBP [12], it showed twin peak at 2857 and $2927 \mathrm{~cm}^{-1}$ attributing to $-\mathrm{NH}_{2}$, a C-N stretch at $1165 \mathrm{~cm}^{-1}$ and $\mathrm{C}=\mathrm{O}$ stretch of carboxylic group at $1615 \mathrm{~cm}^{-1}$. The IR spectra of charge transfer complexes of GBP with NIN, DDQ and TCNE have already been reported by our research colleagues earlier [12]. In the IR spectra of MO and PA complexes of GBP, the doublet

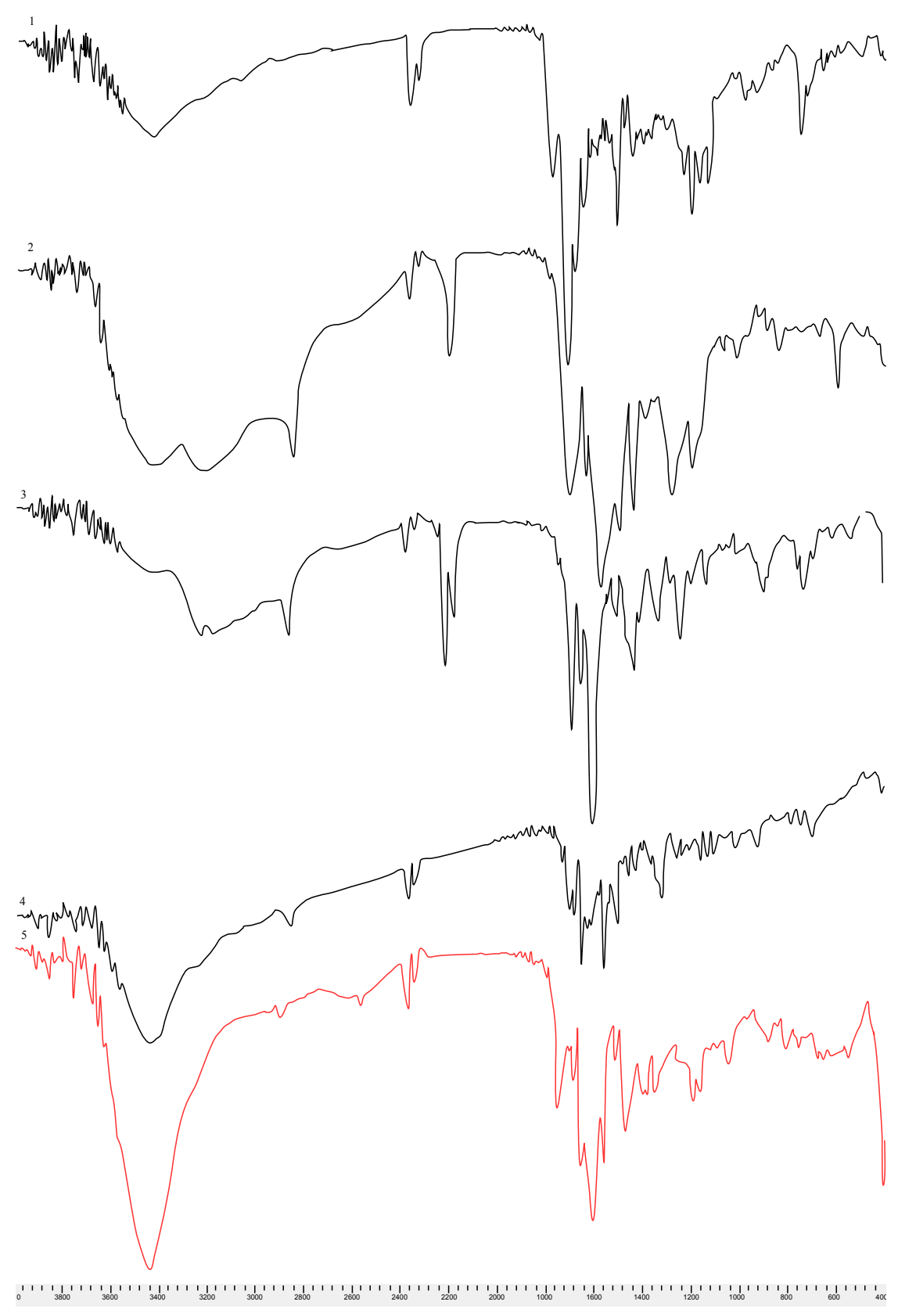

Figure 9: IR spectra of charge transfer complexes of GBP with (1) NIN (2) DDQ (3) TCNE (4) MO (5) PA. 
<smiles>O=C1C(N=c2c(=O)c3ccccc3c2=O)=C(O)c2ccccc21</smiles>

(a)<smiles>N#CC1=C(C#N)C(O)=C(Cl)C(Cl)(NCC2(CC(=O)O)CCCCC2)C1=O</smiles><smiles>N#CC(C#N)C(C#N)(C#N)NCC1(CC(=O)O)CCCCC1</smiles><smiles>[NH3+]CC1(CC(=O)O)CCCCC1</smiles><smiles>O=S(=O)(O)O</smiles><smiles>Cc1ccc(/N=N/c2ccc(N(C)C)cc2)cc1</smiles><smiles>[NH3+]CC1(CC(=O)O)CCCCC1</smiles>

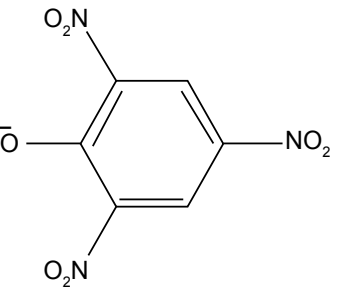

(e)

Figure 10: Charge transfer complexes of GBP with (1) NIN (2) DDQ (3) TCNE (4) MO (5) PA.

peak for $-\mathrm{NH}_{2}$ found absent, confirming the formation of complex. Carbonyl peak shifted to $1710 \mathrm{~cm}^{-1}$ and peaks at 1342 and $1161 \mathrm{~cm}^{-1}$ and also at $650 \mathrm{~cm}^{-1}$ appeared owing to the $\mathrm{S}=\mathrm{O}$ and $\mathrm{S}-\mathrm{O}$ group respectively in GBP-MO complex, where as in GBP-PA complex, carbonyl peak appeared at $1653 \mathrm{~cm}^{-1}$ and two peaks of medium intensity appeared at 1560 and $1320 \mathrm{~cm}^{-1}$ attributed to asymmetric and symmetric stretch of $\mathrm{NO}_{2}$. The $\mathrm{C}=\mathrm{C}$ aromatic stretch appeared at 1510 and $1431 \mathrm{~cm}^{-1}$, while aliphatic $-\mathrm{CH}_{2}$ appeared at $1478 \mathrm{~cm}^{-1}$. Figure 9 represents the IR spectra of GBP complexes. On the basis of spectral characteristics, the structure of complexes is given in figure 10.

\section{Conclusion}

The determination of GBP in bulk and its formulation has been investigated by means of spectrophotometric analysis. The method is based on charge transfer complexes with NIN, DDQ, TCNE, MO and PA. Linear calibration curves were obtained with correlation coefficient greater than 0.998. Spectral characteristics including oscillator's strength, dipole moment, ionization potential, energy of complexes, resonance energy, association constant and Gibb's free energy changes have been determined. Benesi-Hildebrand plots for each complex have been constructed. Further, solid charge transfer complexes of GBP were synthesized and characterized by IR and ${ }^{1} \mathrm{H}-\mathrm{NMR}$ spectroscopy.

\section{Acknowledgement}

Mrs Saeeda Nadir Ali deeply acknowledges Higher Education Commission, Pakistan for providing Indigenous Scholarship for this research work.

\section{References}

1. Pandya KJ, Morrow GR, Roscoe JA, Zhao H, Hickok JT, et al. (2005) Gabapentin for hot flashes in 420 women with breast cancer: a randomised double-blind placebo-controlled trial. Lancet 366: 818-824.

2. Reddy SY, Warner H, Guttuso Jr T, Messing S, DiGrazio W, et al. (2006) Roy M. Pitkin Award. Hypertension 108: 826-832.

3. Dodrill CB, Arnett JL, Hayes AG, Garofalo EA, Greeley CA, et al. (1999) Cognitive abilities and adjustment with gabapentin: results of a multisite study. Epilepsy Res 35: 109-121.
4. Rosenberg JM, Harrell C, Ristic H, Werner RA, de Rosayro AM (1997) The effect of gabapentin on neuropathic pain. Clin J Pain 13: 251-255.

5. Themelis DG, Tzanavaras PD, Boulimari EA (2010) Generic automated fluorimetric assay for the quality control of gamma aminobutyric acid-analogue anti-epileptic drugs using sequential injection. Analytical Letters 43: 905-918.

6. Alqaradawi SY, Nour el-M (2005) Spectroscopic investigation of the novel charge-transfer complex [(phen)(TCNE)(12)] formed in the reaction of phenacetin with tetracyanoethylene. Spectrochim Acta A Mol Biomol Spectrosc 62: $578-581$.

7. AIQaradawi SY, Nour EM (2006) Synthesis and spectroscopic structura studies of the adducts formed in the reaction of aminopyridines with TCNQ. Journal of Molecular Structure 794: 251-254.

8. Sultana N, Arayne MS, Hussain F, Fatima A (2006) Degradation studies of azithromycin and its spectrophotometric determination in pharmaceutical dosage forms. Pak J Pharm Sci 19: 98-103.

9. Arayne MS, Sultana N, Hussain F, Ali SA (2007) Validated Spectrophotometric Method for Quantitative Determination of Simvastatin in Pharmaceutical Formulations and Human serum. Journal of Analytical Chemistry 62: 536-541.

10. Arayne MS, Sultana N, Siddiqui FA, Mirza AZ, Zuberi HM (2008) Spectrophotometric techniques to determine tranexamic acid: Kinetic studies using ninhydrin and direct measuring using ferric chloride. Journal of Molecular Structure 891: 475-480.

11. Arayne MS, Sultana N, Hussain F (2009) Spectrophotometric method for quantitative determination of montelukast in bulk, pharmaceutical formulations and human serum. Journal of Analytical Chemistry 64: 690-695.

12. Siddiqui FA, Arayne MS, Sultana N, Qureshi F, Mirza AZ, et al. (2010) Spectrophotometric determination of gabapentin in pharmaceutical formulations using ninhydrin and pi-acceptors. Eur J Med Chem 45: 2761-2767.

13. al-Zehouri J, al-Madi S, Belal F (2001) Determination of the antiepileptics vigabatrin and gabapentin in dosage forms and biological fluids using Hantzsch reaction. Arzneimittelforschung 51: 97-103.

14. Abdellatef HE, Khali HM (2003) Colorimetric determination of gabapentin in pharmaceutical formulation. J Pharm Biomed Anal 31:209-214.

15. Salem H (2008) Analytical study for the charge-transfer complexes of gabapentin. African Journal of Pharmacy and Pharmacology 2: 136-144.

16. Patel B, Patel J, Singh H, Patel B (2011) Extractive Spectrophotometric 
Citation: Najma S, Saeed Arayne M, Saeeda Nadir A (2013) Charge Transfer Complexes of Gamma Aminobutyric Acid-Analogue, A Neurotransmitter: Synthesis and Spectrophotometric Determination. J Bioanal Biomed 5: 013-021. doi:10.4172/1948-593X.1000075

Methods for the Determination of Gabapentin in Pharmaceutical Dosage Forms. International Journal of Pharmaceutical Sciences and Drug Research 3: 197-201.

17. Abdulrahman SAM, Basavaiah K (2011) Sensitive and selective spectrophotometric determination of gabapentin in capsules using two nitrophenols as chromogenic agents. International Journal of Analytical Chemistry 9

18. Abdulrahman SAM, Basavaiah K (2012) Highly sensitive spectrophotometric method for the determination of gabapentin in capsules using sodium hypochloride. Turk J Pharm Sci 9:113-126.

19. Gujral RS, Haque SM, Shanker P (2009) A sensitive UV spectrophotometric method for the determination of gabapentin. E-Journal of Chemistry 6: 163-170.

20. Ribeiro MF, Santos JL, Lima JL (2007) Piezoelectric pumping in flow analysis: Application to the spectrophotometric determination of gabapentin. Anal Chim Acta 600: 14-20.

21. Jia S, Lee HS, Choi MJ, Hyun Sung S, Sang BH, et al. (2012) Non-Derivatization Method for the Determination of Gabapentin in Pharmaceutical Formulations, Rat Serum and Rat Urine using High Performance Liquid Chromatography Coupled with Charged Aerosol Detection. Current Analytical Chemistry 8: 159167

22. Carlsson KC, Reubsaet JL (2004) Sample preparation and determination of gabapentin in venous and capillary blood using liquid chromatography-tandem mass spectrometry. J Pharm Biomed Anal 34: 415-423.

23. Lin FM, Kou HS, Wu SM, Chen SH, Wu HL (2004) Capillary electrophoresis analysis of gabapentin and vigabatrin in pharmaceutical preparations as ofloxacin derivatives. Analytica Chimica Acta 523: 9-14

24. Belal F, Abdine H, Al-Majed A, Khalil NY (2002) Spectrofluorimetric determination of vigabatrin and gabapentin in urine and dosage forms through derivatization with fluorescamine. J Pharm Biomed Anal 27: 253-260.
25. Jalali F, Arkan E, Bahrami G (2007) Preparation of a gabapentin potentiometric sensor and its application to pharmaceutical analysis. Sensors and Actuators B: Chemical 127: 304-309.

26. Hegde RN, Kumara Swamy BE, Shetti NP, Nandibewoor ST (2009) Electrooxidation and determination of gabapentin at gold electrode. Journal of Electroanalytical Chemistry 635: 51-57.

27. Manera M, Miro M, Ribeiro MF, Estela JM, Cerda V, et al. (2009) Rapid chemiluminometric determination of gabapentin in pharmaceutical formulations exploiting pulsed-flow analysis. Luminescence 24: 10-14.

28. El-Tohamy M, Razeq S, Shalaby A (2012) Electrochemical Sensors fo Determination of Anticonvulsant Drug Gabapentin in Bulk Powder and Pharmaceutical Dosage Forms. Int J Electrochem Sci 7: 5374-5387.

29. Rathore R, Lindeman SV, Kochi JK (1997) Charge-transfer probes fo molecular recognition via steric hindrance in donor-acceptor pairs. J Am Chem Soc 119: 9393-9404.

30. Refat MS, El-Hawary WF, Moussa MA (2011) IR, 1H NMR, mass, XRD and TGA/DTA investigations on the ciprofloxacin/iodine charge-transfer complex. Spectrochim Acta A Mol Biomol Spectrosc 78: 1356-1363.

31. Aloisi GG, Pignataro S (1973) Molecular complexes of substituted thiophen with $\sigma$ and $\pi$ acceptors. Charge transfer spectra and ionization potentials of the donors. J Chem Soc Faraday Trans 1 69: 534-539.

32. Briegleb G, Czekalla J (1960) Z. Physikchem. Frankfurt 24: 237.

33. Benesi HA, Hildebrand JH (1949) A spectrometric investigation of the interaction of iodine with aromatic hydrocarbons. J Am Chem Soc 71: 2703-2707.

34. Martin AN, Swarbrick J, Cammarata A (1969) Physical Pharmacy, (3rdedn), Lee \& Febiger, Philadelphia, 344 